\title{
Airway Pressure Release Ventilation as a Rescue Therapy in Pediatric Acute Respiratory Distress Syndrome (pARDS): Goodwill or Devil?
}

\author{
Shyam Chandrasekhar ${ }^{1} \cdot$ Krishna Mohan Gulla $^{1}$ (ID
}

Received: 7 September 2020 / Accepted: 7 September 2020 / Published online: 17 September 2020

(C) Dr. K C Chaudhuri Foundation 2020

Pediatric Acute Respiratory Distress Syndrome is a significant cause of morbidity and mortality among children admitted to the pediatric intensive care unit. Various ventilation strategies have been used to improve oxygenation and ventilation in pARDS with further avoidance of secondary lung injury. Lung protective strategy using low tidal volume through conventional mechanical ventilation is the standard of care in pARDS. However, evidence on non-conventional ventilation modes such as High frequency oscillatory ventilation (HFOV) and Airway pressure release ventilation (APRV) has been scarce. A recent randomised control trial comparing HFOV and APRV for refractory hypoxemia in pARDS by Lalgudi et al. showed significant increase in mortality in the APRV group which led to premature termination of the trial [1]. APRV, as the name indicates, is a continuous positive pressure with a brief intermittent release phase which allows partial release of the lung volume for carbon dioxide exhalation. The strategies in APRV include Personalized APRV (PAPRV) which uses a $T_{\text {low }}$ based on lung mechanics with a zero $\mathrm{P}_{\text {low }}$ with a $\mathrm{T}_{\text {High }}>90 \%$ of the total breath time and a Fixed APRV (F-APRV) which works with a constant $\mathrm{T}_{\text {low }}$ and a non-zero $\mathrm{P}_{\text {low }}$ with a $\mathrm{T}_{\mathrm{High}}<90 \%$ of the total cycle time [2]. The main advantage of APRV is its ability to maximize the recruitment of alveoli and hence improving oxygenation along with added benefit of spontaneous breathing minimizing the risk of barotrauma [3]. It also has added advantages such as increased comfort for the patient and decreased sedative use $[1,4]$. The contraindication to its use is children who require deep sedation for the underlying disease states like

Krishna Mohan Gulla

mohangulla35@gmail.com

1 Department of Pediatrics, AIIMS, Bhubaneswar, Odisha, India status epilepticus, raised intracranial pressure, severe obstructive airway disease, air leak syndromes [3].

In the retrospective, observational study published in Indian Journal of Pediatrics [5], Yener et al. had used APRV as a rescue therapy in severe pARDS in 30 children with age group of 1 mo to $18 \mathrm{y}$. The study population had a mean age of $32.8 \pm 22.6$ mo with $83 \%$ of them were less than 5-y-old. APRV mode was used in those children who were hypoxemic despite on low tidal volume $(6-8 \mathrm{ml} / \mathrm{kg}), \mathrm{PEEP}>15 \mathrm{~cm} \mathrm{H} \mathrm{H}_{2} \mathrm{O}$ with $>60 \% \mathrm{FiO}_{2}$ on SIMC-PS mode. This mode was initiated on an average $3.2 \pm 2.6 \mathrm{~d}$ (range: $1-11 \mathrm{~d}$ ) following intubation. At $3 \mathrm{~h}$ after APRV initiation, there was significant increase in the $\mathrm{S} / \mathrm{F}$ ratio $(165.1 \pm 13.6$ vs. $131.7 \pm 10.2, p=$ $0.035)$, decrement in peak pressure $(25.4 \pm 1.26$ vs. $29.8 \pm$ $0.60, p<0.001)$ and increment in mean airway pressure $(19.11 \pm 0.97$ vs. $15.32 \pm 1.3, p<0.001)$. Vasopressor requirement and the $\mathrm{pH}$ and venous $\mathrm{CO}_{2}$ values were not significantly different before and after APRV at $3 \mathrm{~h}$. One child had bilateral pneumothorax. Five children died in the cohort and of which 4 children died of refractory hypoxemia. In this study, disease severity indices while transition to APRV could have modified the outcomes. The mortality data is intriguing as a similar study done by Yehya et al. [6] showed a mortality of whopping $63 \%$ in their study group of severe pARDS. As it is a known fact that younger children have a greater chest wall compliance than that of the adults, the pressure given might generate a higher tidal volume and hence can be detrimental in a spontaneously breathing child on theoretical grounds [2]. Meta-analysis in adults including six randomised control trials have shown insignificant differences in morbidity and mortality among those treated with APRV or conventional ventilation [7]. However, the role of APRV in critically ill pARDS children is still not clear [8]. Though APRV mode is not widely practiced by pediatric intensivists due to lack of evidence, it does not mean absence of evidence. APRV can be used as a rescue mode in case of refractory hypoxemia where HFO or 
ECMO facilities are not widely available like the case in India. Further high quality multicenter RCTs are required to establish APRV as a standard rescue therapy in pARDS.

\section{Compliance with Ethical Standards}

Conflict of Interest None.

\section{References}

1. Lalgudi Ganesan S, Jayashree M, Chandra Singhi S, Bansal A. Airway pressure release ventilation in pediatric acute respiratory distress syndrome. a randomized controlled trial. Am J Respir Crit Care Med. 2018;198:1199-207.

2. Lalgudi Ganesan S. Airway pressure release ventilation in children. Curr Opin Crit Care. 2019;25:63-70.

3. Daoud EG. Airway pressure release ventilation. Ann Thorac Med. 2007;2:176-9.
4. Zhou Y, Jin X, Lv Y, et al. Early application of airway pressure release ventilation may reduce the duration of mechanical ventilation in acute respiratory distress syndrome. Intensive Care Med. 2017;43: $1648-59$.

5. Yener N, Üdürgücü $M$. Airway pressure release ventilation as a rescue therapy in pediatric acute respiratory distress syndrome. Indian J Pediatr. 2020. https://doi.org/10.1007/s12098-020-03235w.

6. Yehya N, Topjian A, Lin R, Berg R, Thomas N, Friess S. High frequency oscillation and airway pressure release ventilation in pediatric respiratory failure. Pediatr Pulmonol. 2014. https://doi.org/10. 1002/ppul.22853.

7. Bajaj A, Rathor P, Kabak B, et al. Efficacy of airway pressure release ventilation in critically ill patients: a meta-analysis of randomized controlled trials. Am J Respir Crit Care Med. 2015;191:A1195.

8. Chandelia S, Jain S. Severe pediatric acute respiratory distress syndrome due to scrub typhus: successful ventilation with airway pressure release ventilation mode after becoming refractory to protective ventilation. Indian J Crit Care Med. 2017;21:326-8.

Publisher's note Springer Nature remains neutral with regard to jurisdictional claims in published maps and institutional affiliations. 